\title{
With Respect to Quantum Perspective Model, Can Euler Numbers be Related to B1ochemıstry?
}

By Tahir Ölmez

Selcuk University

Abstract- This article researches whether there is a link between Euler's numbers and genetic codes. At first, the sum of the numbers of the first fifteen "15" digits of Euler's numbers after the comma are converted to bases in genetic codes. Secondly, after the comma, Euler's numbers with eighteen fifteen groups are converted to nucleotide bases. So, the results obtained by this way are expressed as nucleotide bases (A, T, C, G, U). (A)Adenine, (T)Thymine, (C)Cytosine, (G), Guanine, (U)Uracil. Thirdly, the search result is similar to ZEBRAFISH-DANIO RERIO, and even bat coronavirus after the NCBI (National Biotechnology Information Center) searched this sequence "AUGUUGAUAUTAAUCATC". Fourtly, the genetic codes of Zebrafish have been proven to be very similar to human genetic codes. Fifthly, multiple spawning of these fish species also means that Euler's numbers are increasing. In sum, the relationship between the Euler's numbers in mathematical science and the atomic weights of atomic elements in genetic codes also shed lights on Biochemistry.

Keywords: zebrafish-danio rerio, biochemistry, euler's numbers, bat coronavirus, quantum perspective model, and NCBI (national biotechnology information center).

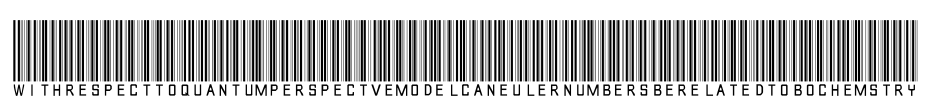

Strictly as per the compliance and regulations of:

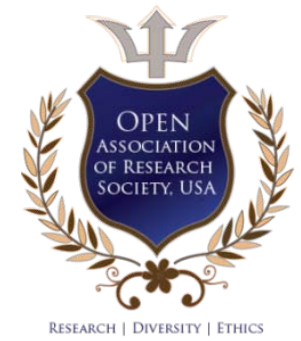

(c) 2020. Tahir Ölmez. This is a research/review paper, distributed under the terms of the Creative Commons AttributionNoncommercial 3.0 Unported License http://creativecommons.org /licenses/by-nc/3.0/), permitting all non commercial use, distribution, and reproduction in any medium, provided the original work is properly cited. 

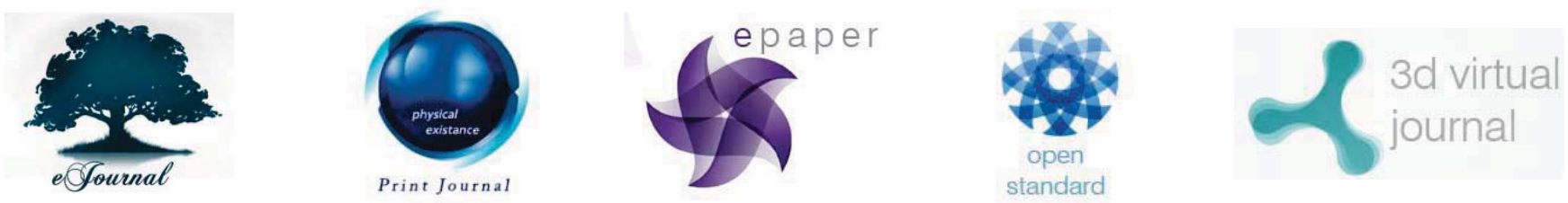

With Respect to Quantum Perspective Model, Can Euler Numbers be Related to Biochemistry?

\author{
Tahir Ölmez
}

Abstract-This article researches whether there is a link between Euler's numbers and genetic codes. At first, the sum of the numbers of the first fifteen "15" digits of Euler's numbers after the comma are converted to bases in genetic codes. Secondly, after the comma, Euler's numbers with eighteen fifteen groups are converted to nucleotide bases. So, the results obtained by this way are expressed as nucleotide bases (A, T, C, G, U). (A)Adenine, (T)Thymine, (C)Cytosine, (G), Guanine, (U)Uracil. Thirdly, the search result is similar to ZEBRAFISH-DANIO RERIO, and even bat coronavirus after the NCBI (National Biotechnology Information Center) searched this sequence "AUGUUGAUAUTAAUCATC". Fourtly, the genetic codes of Zebrafish have been proven to be very similar to human genetic codes. Fifthly, multiple spawning of these fish species also means that Euler's numbers are increasing. In sum, the relationship between the Euler's numbers in mathematical science and the atomic weights of atomic elements in genetic codes also shed lights on Biochemistry.

Keywords: zebrafish-danio rerio, biochemistry, euler's numbers, bat coronavirus, quantum perspective model, and NCBI (national biotechnology information center).

\title{
I. Euler Numbers
}

Euler's numbers are e:

2.7182818284590452353602874713526624977572470936999595749669676277240766303535 47594571382178525166427427466391932003059921817413596629043572900334295260595 63073813232862794349076323382988075319525101901157383418793070215408914993488 4167509244761460668082264800168477411853 [1]

\section{Methods and Discussion}

The chemical structures of bases include Carbon(C), Nitrogen (N), Oxygen (O), and Hydrogen $(\mathrm{H})$. Calculation of bases with chemical atoms (See also Table-1). (Ölmez $\mathrm{T}, 2020)$.

Author: Selçuk University, Social Sciences Dept., Selcuklu/Konya. e-mails: bsonmez3@gmail.com, tolmez123@yahoo.com 
Table 1: Representation of nucleotide bases (A, T, C, G and U) in chemical atoms

\begin{tabular}{|c|c|c|c|c|c|}
\hline ATOMS / NUCLEOTIDE BASES & C=6 & H=1 & O=8 & N=7 & SUM \\
\hline ADENINE: C5H5N5 & 5 & 5 & - & 5 & 70 \\
\hline THYMINE: C5H6N2O2 & 5 & 6 & 2 & 2 & 66 \\
\hline CYTOSINE: C4H5N3O1 & 4 & 5 & 1 & 3 & 64 \\
\hline GUANINE: C5H5N5O1 & 5 & 5 & 1 & 5 & 78 \\
\hline URACIL : C4H4N2O2 & 4 & 4 & 2 & 2 & 58 \\
\hline
\end{tabular}

The atomic numbers of them: Carbon $(\mathrm{C}): 6$, Nitrogen $(\mathrm{N}): 7$, Oxygen $(\mathrm{O}): 8$, Hydrogen (H): 1 (Wieser E M et al, 2013).

The chemical structures of bases (A, T, C, G, and U) are shown at below.

8 (Ölmez T, 2020)
(A) Adenine: C5H5N5:70;
(T) Thymine: C5H6N2O2:66,
(C) Cytosine: C4H5N3O1:64,
(G) Guanine: C5H5N5O1:78, and
(U) Uracil: C4H4N2O2: 58

(Lodish $\mathrm{H}$ et al, 2018).

\section{Calculation of Euler Numbers and Genetic Codes}

Euler's numbers are e:

2.7182818284590452353602874713526624977572470936999595749669676277240766303535 47594571382178525166427427466391932003059921817413596629043572900334295260595 63073813232862794349076323382988075319525101901157383418793070215408914993488 4167509244761460668082264800168477411853 [1]

Euler's numbers fifteen groups can be shown as [AUGUUGAUAUTAAUCATC]

The first fifteen groups of Euler's numbers after the comma:

$7+1+8+2+8+1+8+2+8+4+5+9+0+4+5+9+0+4+5=72$. Just like as in Adenine (A): 70 .

The second fifteen groups of Euler's numbers after the comma:

$2+3+5+3+6+0+2+8+7+4+7+1+3+5+2=58$. Just like as in Uracil (U): 58 .

The third fifteen groups of Euler's numbers after the comma:

$6+6+2+4+9+7+7+5+7+2+4+7+0+9+3=78$. Just like as in Guanine $(\mathrm{G}): 78$

The fourth fifteen groups of Euler's numbers after the comma:

$6+9+9+9+5+9+5+7+4+9+6+6+9+6+7=106^{*}$. Just like as in Uracil (U): $58^{*}$

The fifth fifteen groups of Euler's numbers after the comma:

$6+2+7+7+2+4+0+7+6+6+3+0+3+5+3=61$. Just like as in Uracil (U): 58 . 
The sixth fifteen groups of Euler's numbers after the comma:

$5+4+7+5+9+4+5+7+1+3+8+2+1+7+8=76$. Just like as in Guanine $(\mathrm{G}): 78$.

The seventh fifteen groups of Euler's numbers after the comma:

$5+2+5+1+6+6+4+2+7+4+2+7+4+6+6=67$. Just like as in Adenine $(\mathrm{A}): 70$

The eighth fifteen groups of Euler's numbers after the comma:

$3+9+1+9+3+2+0+0+3+0+5+9+9+2+1=56$. Just like as in Uracil (U): 58

The ninth fifteen groups of Euler's numbers after the comma:

$8+1+7+4+1+3+5+9+6+6+2+9+0+4+3=68$. Just like as in Adenine $(\mathrm{A}): 70$

The tenth fifteen groups of Euler's numbers after the comma:

$5+7+2+9+0+0+3+3+4+2+9+5+2+6+0=57$. Just like as in Uracil (U): 58 .

The eleventh fifteen groups of Euler's numbers after the comma:

$5+9+5+6+3+0+7+3+8+1+3+2+3+2+8=65$. Just like as in Thymine $(\mathrm{T}): 66$

The twelfth fifteen groups of Euler's numbers after the comma:

$6+2+7+9+4+3+4+9+0+7+6+3+2+3+3=68$. Just like as in Adenine $(\mathrm{A}): 70$

The thirteenth fifteen groups of Euler's numbers after the comma:

$8+2+9+8+8+0+7+5+3+1+9+5+2+5+1=73$. Just like as in Adenine $(A): 70$

The fourteenth fifteen groups of Euler's numbers after the comma:

$0+1+9+0+1+1+5+7+3+8+3+4+1+8+7=58$. Just like as in Adenine (U): 58

The fifteenth fifteen groups of Euler's numbers after the comma:

$9+3+0+7+0+2+1+5+4+0+8+9+1+4+9=62$. Just like as in Uracil $(\mathrm{C}): 64$

The sixteenth fifteen groups of Euler's numbers after the comma:

$9+3+4+8+8+4+1+6+7+5+0+9+2+4+4=74$. Just like as in Adenine $(\mathrm{A}): 70$

The seventeenth fifteen groups of Euler's numbers after the comma:

$7+6+1+4+6+0+6+6+8+0+8+2+2+6+4=66$. Just like as in Thymine $(\mathrm{T}): 66$

The eighteenth fifteen groups of Euler's numbers after the comma:

$8+0+0+1+6+8+4+7+7+4+1+1+8+5+3=63$. Just like as in Cytosine $(\mathrm{C}): 64$

This sequence is" [AUGUUGAUAUTAAUCATC]. Let me try to explain this sequence with the "Quantum Perspective Model."For example, The first fifteen groups of Euler's numbers after comma equal to Adenine (A):68 with the lack of two"2" Hydrogen bonds(H:1).(Remember, See Table-1; (A)Adenine:70) This result could be the meaning of Euler's numbers sequence in fifteen groups. [AUGUUGAUAUTAAUCATC]. The fourth fifteen groups of Euler's numbers after the comma is regarded as Uracil (U). Because Phosphate group "PO4" $\left(\mathrm{P}: 15^{*} 1+\mathrm{O}: 8^{*} 4=47\right)$ and Uracil (U): 58 and one 
Hydrogen $(\mathrm{H})$. Totally,47+58+1:106*[5]. The fifth, sixth and seventh fifteen groups of Euler's numbers after the comma is UGA [Uracil, Guanine and Adenine] which also means STOP codon [13]. So, the deviations in the calculation of Euler's numbers can be derived from the Adenine (A) - Thymine (T) Hydrogen bonds because of Adenine (A) pairs with Thymine $(\mathrm{T})$ by two hydrogen bonds. Cytosine $(\mathrm{C})$ - Guanine $(\mathrm{G})$ pairs with by three hydrogen bonds [3]. The reason for the lack of hydrogen bonds: Hydrogen bonding is a very versatile attraction. (Ölmez T, 2020) Hydrogen bonds are relatively weak and easily broken by increasing hardness (Farrell R E, 2010).

\section{a) The National Center for Biotechnology Information (NCBI) results for Euler's numbers}

After searching Euler's numbers result [AUGUUGAUAUTAAUCATC] in NCBI databases, some conceptual relationships can be found with bony fish. Types of bony fish are based on Zebra fish(DANIO RERIO) (See FIGURE -4), European star fish, blunt-snouted clingfish, pinecone soldierfish, orbiculate cardinal fish and crown of thorns star fish (See FIGURE -1). Types of other living creatures are human chromoseme18, domestic cat, European eel, domestic cat, American alligator, common sunflower, wine grape, golden and black snub-nosed monkey, green monkey, Rhesus monkey, house fly, giant panda, fall armyworm, Porchine epidemic diarrhea virusan, and chinese hamster[4] (See FIGURE -2 ). The most interesting result of this research result is bat coronavirus(spike protein -chaerephon bat coronavirus ADX59458.1) [11] (See FIGURE -3).

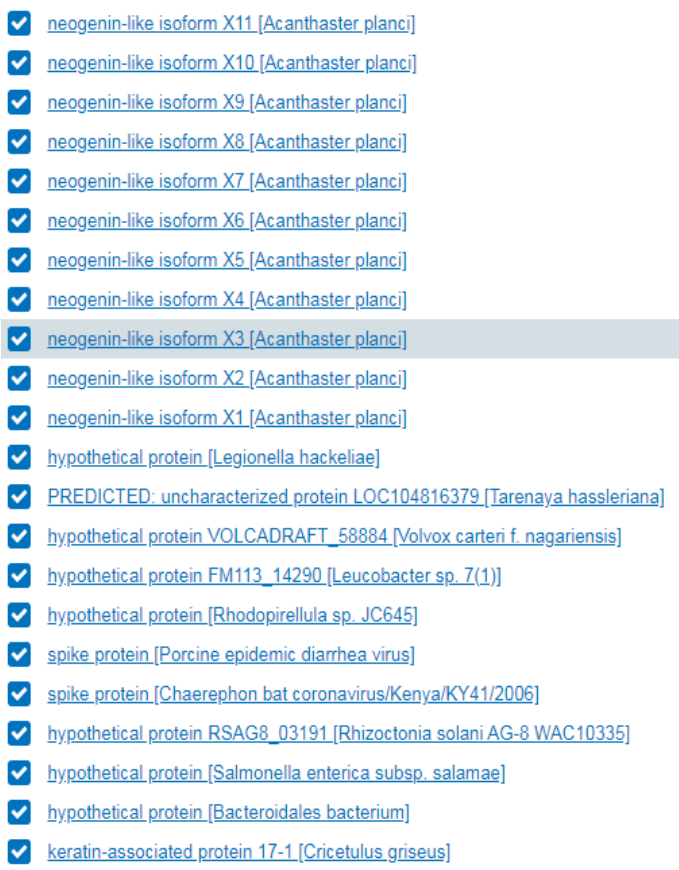

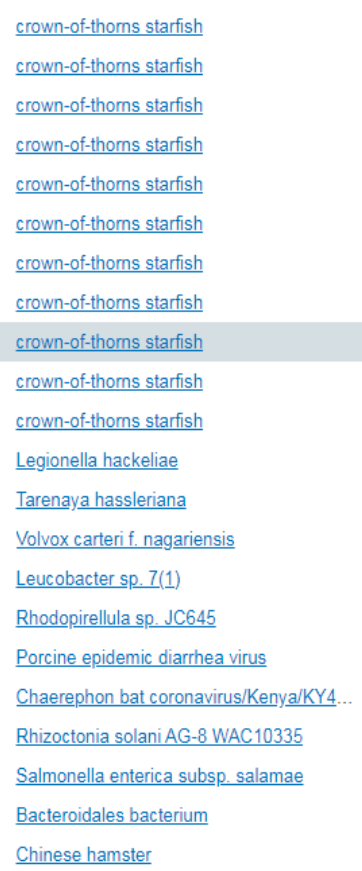

$\begin{array}{lllllll}33.3 & 84.6 & 100 \% & 13 & 30.00 \% & 2112 & \underline{\text { XP_022084118.1 }} \\ 33.3 & 84.6 & 100 \% & 13 & 30.00 \% & 2114 & \underline{\text { XP_022084109.1 }} \\ 33.3 & 84.6 & 100 \% & 13 & 30.00 \% & 2117 & \underline{\text { XP_022084103.1 }} \\ 33.3 & 84.6 & 100 \% & 13 & 30.00 \% & 2130 & \underline{\text { XP_022084096.1 }} \\ 33.3 & 84.6 & 100 \% & 13 & 30.00 \% & 2162 & \underline{\text { XP_022084087.1 }} \\ 33.3 & 84.6 & 100 \% & 13 & 30.00 \% & 2166 & \underline{\text { XP_022084078.1 }} \\ 33.3 & 84.6 & 100 \% & 13 & 30.00 \% & 2171 & \underline{\text { XP_022084069.1 }} \\ 33.3 & 84.6 & 100 \% & 13 & 30.00 \% & 2180 & \underline{\text { XP_022084061.1 }} \\ 33.3 & 84.6 & 100 \% & 13 & 30.00 \% & 2182 & \underline{\text { XP_022084052.1 }} \\ 33.3 & 84.6 & 100 \% & 13 & 30.00 \% & 2184 & \underline{\text { XP_022084043.1 }} \\ 33.3 & 84.6 & 100 \% & 13 & 30.00 \% & 2198 & \underline{\text { XP_022084033.1 }} \\ 32.9 & 32.9 & 83 \% & 17 & 28.57 \% & 45 & \underline{\text { WP_172480797.1 }} \\ 32.9 & 32.9 & 83 \% & 18 & 30.43 \% & 101 & \underline{\text { XP_010543517.1 }} \\ 32.9 & 32.9 & 94 \% & 18 & 29.41 \% & 116 & \underline{\text { XP_002948916.1 }} \\ 32.9 & 32.9 & 83 \% & 18 & 29.41 \% & 159 & \underline{\text { SJN12217.1 }} \\ 32.9 & 32.9 & 88 \% & 18 & 28.57 \% & 275 & \underline{\text { WP_150078846.1 }} \\ 32.9 & 60.7 & 83 \% & 18 & 26.67 \% & 1386 & \underline{\text { AEW24858.1 }} \\ 32.9 & 32.9 & 88 \% & 18 & 31.25 \% & 1386 & \underline{\text { ADX59458.1 }} \\ 32.5 & 32.5 & 77 \% & 22 & 26.67 \% & 40 & \underline{\text { KDN47771.1 }} \\ 32.5 & 92.7 & 83 \% & 25 & 21.74 \% & 68 & \underline{\text { EDU0501388.1 }} \\ 32.5 & 32.5 & 100 \% & 25 & 28.00 \% & 78 & \underline{\text { MBE6332989.1 }} \\ 32.5 & 58.5 & 94 \% & 25 & 21.05 \% & 112 & \underline{\text { XP_035317626.1 }}\end{array}$

Figure 1: The NCBI (National Biotechnology Information Center) Result for Nucleotide Sequence "AUGUUGAUAUTAAUCATC" [4] 


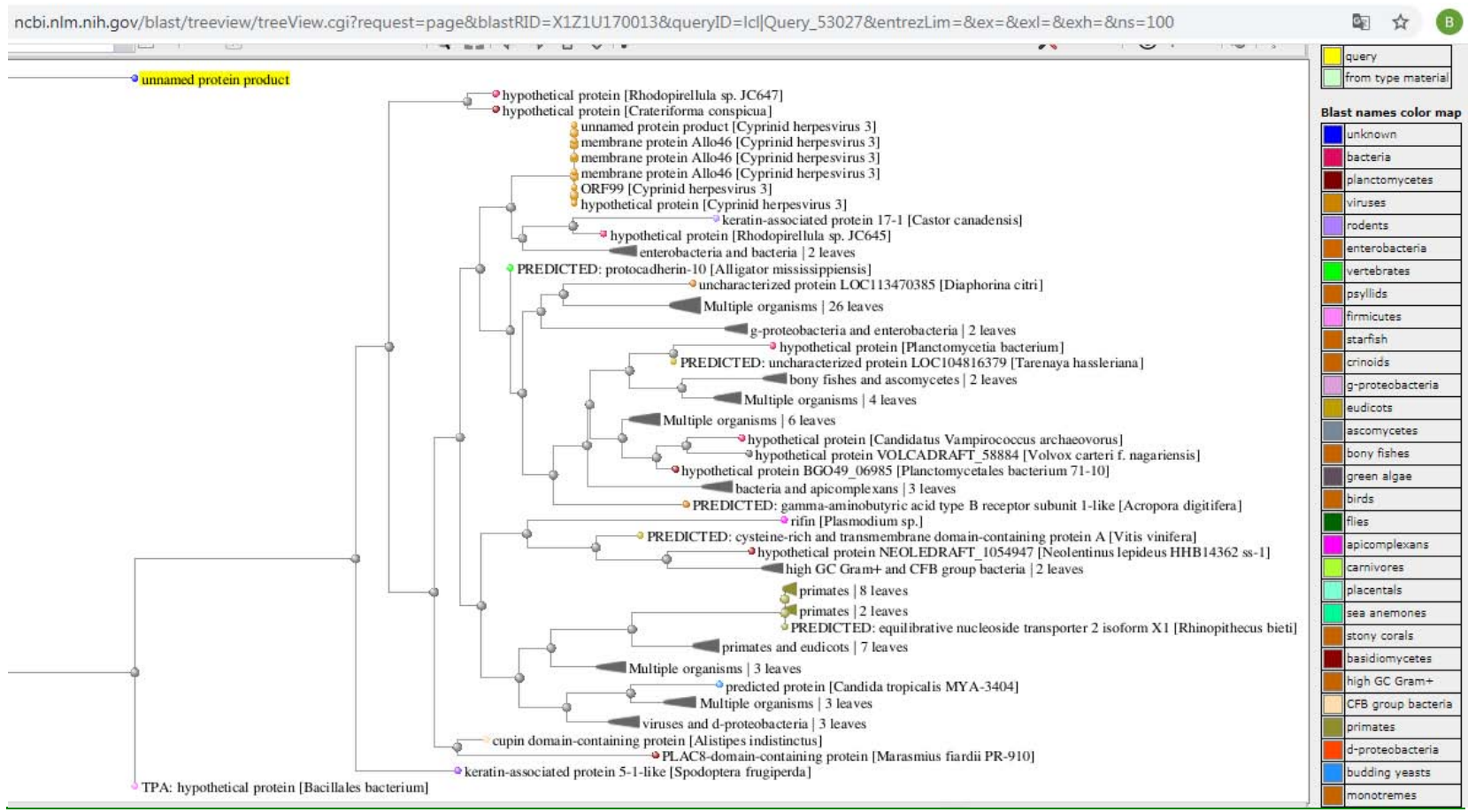

Figure 2: The NCBI (National Biotechnology Information Center) Result Blast Tree View Widget for "AUGUUGAUAUTAAUCATC" Nucleotide Sequence [4]

\begin{tabular}{|c|c|c|c|c|c|c|c|c|}
\hline neogenin-like isoform X10 [Acanthaster planci] & crown-of-thoms starifish & 33.3 & 84.6 & $100 \%$ & 13 & $30.00 \%$ & 2114 & $\underline{X P} 022084109.1$ \\
\hline neogenin-like isoform X9 [Acanthaster planci] & crown-of-thoms starifish & 33.3 & 84.6 & $100 \%$ & 13 & $30.00 \%$ & 2117 & $\underline{X P \_022084103.1}$ \\
\hline neogenin-like isoform X8 [Acanthaster planci] & crown-of-thoms starish & 33.3 & 84.6 & $100 \%$ & 13 & $30.00 \%$ & 2130 & $\underline{X P \_22084096.1}$ \\
\hline neogenin-like isoform X7 [Acanthaster planci] & crown-of-thoms starifish & 33.3 & 84.6 & $100 \%$ & 13 & $30.00 \%$ & 2162 & $\underline{X P \_022084087.1}$ \\
\hline neogenin-like isoform X6 [Acanthaster planci] & crown-of-thorns starifish & 33.3 & 84.6 & $100 \%$ & 13 & $30.00 \%$ & 2166 & $\underline{X P} 022084078.1$ \\
\hline neogenin-like isoform X5 [Acanthaster planci] & crown-of-thoms starifish & 33.3 & 84.6 & $100 \%$ & 13 & $30.00 \%$ & 2171 & $\underline{X P \_022084069.1}$ \\
\hline neogenin-like isoform X4 [Acanthaster planci] & crown-of-thoms starish & 33.3 & 84.6 & $100 \%$ & 13 & $30.00 \%$ & 2180 & $\underline{X P \_022084061.1}$ \\
\hline neogenin-like isoform X3 [Acanthaster planci] & crown-of-thoms starish & 33.3 & 84.6 & $100 \%$ & 13 & $30.00 \%$ & 2182 & $\underline{X P \_022084052.1}$ \\
\hline neogenin-like isoform X2 [Acanthaster planci] & crown-of-thorns starifish & 33.3 & 84.6 & $100 \%$ & 13 & $30.00 \%$ & 2184 & $\underline{X P \_22084043.1}$ \\
\hline neogenin-like isoform X1 [Acanthaster planci] & crown-of-thoms starifish & 33.3 & 84.6 & $100 \%$ & 13 & $30.00 \%$ & 2198 & $\underline{X P} 022084033.1$ \\
\hline hypothetical protein [Legionella hackeliae] & $\underline{\text { Legionella hackeliae }}$ & 32.9 & 32.9 & $83 \%$ & 17 & $28.57 \%$ & 45 & $\underline{\text { WP_172480797.1 }}$ \\
\hline PREDICTED: uncharacterized protein LOC104816379 [Tarenaya hassleriana] & Tarenaya hassleriana & 32.9 & 32.9 & $83 \%$ & 18 & $30.43 \%$ & 101 & $\underline{X P \_010543517.1}$ \\
\hline hypothetical protein VOLCADRAFT_58884 [Volvox carter if. nagariensis] & $\underline{\text { Volvox carterif. nagariensis }}$ & 32.9 & 32.9 & $94 \%$ & 18 & $29.41 \%$ & 116 & $\underline{X P \_02948916.1}$ \\
\hline hypothetical protein FM113 14290 [Leucobacter sp. 7(1)] & Leucobacter sp. 7(1) & 32.9 & 32.9 & $83 \%$ & 18 & $29.41 \%$ & 159 & $\underline{\text { SJN12217.1 }}$ \\
\hline hypothetical protein [Rhodopirellula sp. JC645] & Rhodopirellula sp. JC645 & 32.9 & 32.9 & $88 \%$ & 18 & $28.57 \%$ & 275 & WP_150078846.1 \\
\hline spike protein [Porcine epidemic diarrhea virus] & $\underline{\text { Porcine epidemic diarrhea virus }}$ & 32.9 & 60.7 & $83 \%$ & 18 & $26.67 \%$ & 1386 & AEW24858.1 \\
\hline spike protein [Chaerephon bat coronavirus/Kenya/KY41/2006] & Chaerephon bat coronavirus/Kenya/KY4. & 32.9 & 32.9 & $88 \%$ & 18 & $31.25 \%$ & 1386 & $\underline{A D X 59458.1}$ \\
\hline hypothetical protein RSAG8_03191 [Rhizoctonia solani AG-8 WAC10335] & Rhizoctonia solani AG-8 WAC10335 & 32.5 & 32.5 & $77 \%$ & 23 & $26.67 \%$ & 40 & $\underline{\text { KDN47771.1 }}$ \\
\hline hypothetical protein [Salmonella enterica subsp. salamae] & $\underline{\text { Salmonella enterica subsp. salamae }}$ & 32.5 & 92.7 & $83 \%$ & 25 & $21.74 \%$ & 68 & EDU0501388.1 \\
\hline hypothetical protein [Bacteroidales bacterium] & Bacteroidales bacterium & 32.5 & 32.5 & $100 \%$ & 25 & $28.00 \%$ & 78 & MBE6332989.1 \\
\hline keratin-associated protein 17-1 [Cricetulus griseus] & Chinese hamster & 32.5 & 58.5 & $94 \%$ & 25 & $21.05 \%$ & 112 & $\underline{X P \_35317626.1}$ \\
\hline
\end{tabular}

Figure 3: The NCBI (National Biotechnology Information Center) Result for bat coronavirus [4] 


\section{Results}

The relationships between the numerical value of the numbers of light velocities against genetic codes were researched based on the quantum perspective model (Köklü K, 2019b). Further, after the manual division of Twenty-Two (22) to seven (7) numbers, each of the fourteen (14) number sequences obtained after the comma was followed by approximately continuously same nucleotide base codes (Köklü K, 2019a). If you take $\mathrm{Pi}$ numbers as fourteen sequences a hundred times, The output of the genetic code is [ATU]. this result is similar to ZEBRAFISH- DANIO RERIO in NCBI Blast. (See FIGURE -4). [4] (NCBI: The National Center for Biotechnology).This fish is a perfect favorite example of many experiments related to biology and gene sequences. [2] The square of the speed of light is written just like those gene sequences: [UUATACCTC] or [UUAUACCTC].After searching three times this sequence (27), the output of this nucleotide blast is similar to Zebrafish-Danio Rerio. (Köklü K, 2019b). In other words, the output of this nucleotide blast is common to Zebra fish in groups of fourteen pi numbers and Euler numbers in groups of fifteen. In sum, the common feature of the square of the speed of light and pi numbers and Euler numbers is Zebra fish. Insulin receptor (IR) signaling is thought to be important in growth and development. The role of insulin receptor signaling in Zebrafish embryogenesis has vital roles in vertebrate embryogenesis and growth [9].Also, new genetic models have been produced to study resistance to the thyroid hormone receptor in Zebrafish [10].Besides, even both the CAAT Box and TATA Box NCBI results in consist of bony fishes(Denticle Herring).In other words, CAAT Box and TATA Box are also related to the golden ratio. Remember, the NCBI result of Euler's numbers also consist of bony fishes (Zebrafish) ,too. (Ölmez T, 2020). Denticle Herring is the most primitive living clupeiform. [6].Interestingly, it also consists of "phosphoserine phosphatase" protein coding [7].Let alone, the length of it's 15(fifteen)cm.[8]Remember, this research is taken Euler's numbers as fifteen groups, too. Monkeys and humans have a different number of chromosomes, but they probably have the same number of genes. [12] This similarity can be regarded as a Quantum Perspective Model. In summary, this similarity may be the beginning of the mutual relations of the sciences based on the Quantum Perspective Model at minor level systems. Namely, atoms with the smallest base structure can be taken as a small unit of analysis from the same point of view as mathematical numbers. As a result, with this quantum perspective model, the relationships between chemical formulas and numbers have introduced different paradigms to obtain new clues. 


\begin{tabular}{|c|c|c|c|c|c|c|c|c|}
\hline 4_Tbi_b3v08 & Timema bart... & 34.2 & 34.2 & $94 \%$ & 36 & $100.00 \%$ & 353296 & $\underline{\mathrm{OD} 564569.1}$ \\
\hline PREDICTED: Patiria miniata uncharacterized LOC119723493 (LOC119723493), transcript variant X1. & bat star & 34.2 & 34.2 & $94 \%$ & 36 & $100.00 \%$ & 3973 & $\underline{X M \_038194174.1}$ \\
\hline Moraxella nonliquefaciens strain FDAARGOS_869 chromosome, complete genome & Moraxella no... & 34.2 & 34.2 & $94 \%$ & 36 & $100.00 \%$ & 2272684 & $\underline{\mathrm{CP} 065728.1}$ \\
\hline PREDICTED: Glossina fuscipes uncharacterized LOC119642928 (LOC119642928), transcript variant X. & Glossina fusc... & 34.2 & 34.2 & $94 \%$ & 36 & $100.00 \%$ & 1955 & $\underline{X M \_038042244.1}$ \\
\hline PREDICTED: Glossina fuscipes uncharacterized LOC119642928 (LOC119642928), transcript variant X. & Glossina fusc... & 34.2 & 34.2 & $94 \%$ & 36 & $100.00 \%$ & 2049 & $\underline{X M \_038042243.1}$ \\
\hline 2_Tsi_b3v08 & Timema shep... & 34.2 & 34.2 & $94 \%$ & 36 & $100.00 \%$ & 113746 & $\underline{\mathrm{OC} 002461.1}$ \\
\hline 2_Tsi_b3v08 & $\underline{\text { Timema shep... }}$ & 34.2 & 34.2 & $94 \%$ & 36 & $100.00 \%$ & 184815 & $\underline{\mathrm{OC} 001171.1}$ \\
\hline Darwinula stevensoni & Darwinula ste... & 34.2 & 34.2 & $94 \%$ & 36 & $100.00 \%$ & 30022 & $\underline{\text { LR903044.1 }}$ \\
\hline Corylus avellana genome assembly. chromosome: ca2 & Corylus avell... & 34.2 & 136 & $94 \%$ & 36 & $100.00 \%$ & 50858233 & $\underline{\text { LR899424.1 }}$ \\
\hline Homo sapiens DNA, chromosome 18 , nearly complete genome & human & 34.2 & 34.2 & $94 \%$ & 36 & $100.00 \%$ & 77846715 & AP023478.1 \\
\hline Vagococcus carniphilus strain ATCC BAA- 640 chromosome, complete genome & Vagococcus c... & 34.2 & 34.2 & $94 \%$ & 36 & $100.00 \%$ & 3020833 & $\underline{\mathrm{CP} 060720.1}$ \\
\hline Staphyloc occus epidermidis strain LM087, complete genome & Staphylococc... & 34.2 & 34.2 & $94 \%$ & 36 & $100.00 \%$ & 2494355 & $\underline{\mathrm{CP} 060528.1}$ \\
\hline Torulaspora sp. CBS 2947 strain CBS2947 chromosome 1 & Torulaspora s... & 34.2 & 34.2 & $94 \%$ & 36 & $100.00 \%$ & 1700142 & $\underline{\mathrm{CP} 059267.1}$ \\
\hline PREDICTED: Anguilla anguilla major histocompatibility complex class I-related gene protein-like (LOC1... & European eel & 34.2 & 34.2 & $94 \%$ & 36 & $100.00 \%$ & 4118 & $\underline{X M \_035425578.1}$ \\
\hline Danio rerio genome assembly. chromosome: 21 & zebrafish & 34.2 & 66.4 & $94 \%$ & 36 & $100.00 \%$ & 48052324 & $\underline{\text { LR812058.1 }}$ \\
\hline Danio rerio genome assembly, chromosome: 21 & zebrafish & 34.2 & 66.4 & $94 \%$ & 36 & $100.00 \%$ & 43492497 & $\underline{\text { LR812614.1 }}$ \\
\hline Danio rerio strain Nadia (NA) genome assembly, chromosome: 21 & zebrafish & 34.2 & 34.2 & $94 \%$ & 36 & $100.00 \%$ & 44761126 & $\underline{\text { LR812589.1 }}$ \\
\hline Danio rerio genome assembly, chromosome: 8 & zebrafish & 34.2 & 34.2 & $94 \%$ & 36 & $100.00 \%$ & 55327790 & $\underline{\text { LR812070.1 }}$ \\
\hline Carpoglyphus lactis mitochondrion, complete genome & prune mite & 34.2 & 34.2 & $94 \%$ & 36 & $100.00 \%$ & 14060 & MN073839.1 \\
\hline Felis catus Senzu DNA, chromosome: D2, American Shorthair breed & domestic cat & 34.2 & 66.4 & $94 \%$ & 36 & $100.00 \%$ & 90643714 & AP023162.1 \\
\hline PREDICTED: Cyclopterus lumpus A-kinase anchoring.protein 13 (akap13), transcript variant X6 , mRNA & lumpfish & 34.2 & 34.2 & $94 \%$ & 36 & $100.00 \%$ & 7215 & $\underline{X M \_034536038.1}$ \\
\hline PREDICTED: Cyclopterus lumpus A-kinase anchoring.protein 13 (akap13), transcript var & $\underline{\text { lumpfish }}$ & 34.2 & 34.2 & $94 \%$ & 36 & $100.00 \%$ & 7638 & $\underline{X M \_034536036.1}$ \\
\hline
\end{tabular}

Figure 4: The NCBI (National Biotechnology Information Center) Result for Zebra fish [4]

\section{Conclusion}

First, the results of this research can be summarized by obtaining Euler's numbers through the chemical structure of chemical elements. At a minor level, Euler's numbers can be thought of as an indicator of chemical formulas. One of the results of both Biochemistry and Mathematics common feature is NCBI blast results. Because these are bony fishes especially DANIO RERIO. Even not only the NCBI result of pi and square number of light is DANIO RERIO, but also NCBI result of Euler's numbers is DANIO RERIO. Since fish are one of the vertebrates that make the most eggs, this is similar to Euler's numbers in terms of multifunctional. This may be an indicator of the Euler's numbers for living things, especially fish.

Finally, at a macro level, the calculation results of Euler's numbers with chemical structures (especially A, T, C, G, and U) are related to both Biochemistry and Mathematics. Briefly, Euler's numbers are not only attributed to numbers in Mathematics but also attributed to chemical formulas of Biochemistry (Carbon(C), Nitrogen $(\mathrm{N})$, Oxygen $(\mathrm{O})$, and Hydrogen $(\mathrm{H})$ ). In summary, this similarity may be the beginning of the mutual relations of the sciences on based on Quantum Perspective Model at minor level systems. Namely, atoms with the smallest base structure can be taken as a small unit of analysis from the same point of view as mathematical numbers.

\section{References Références Referencias}

1. Farrell R E. RNA Methodologies A Laboratory Guide For Isolation and Characterization. 4th Edition, Amsterdam Elsevier Acad. Press, Pennsylvania State University York, 2010; 704-710.

2. Köklü K. A Quantum Perspective Model to Genetic Codes through Various Sciences. Neuro Quantology April 2019a; 17:3. DOI: 10.14704/nq.2019.17.3.1974. 
3. Köklü K. Is Relativity Theory Also Valid in Biogenetics and Mathematics? Neuro Quantology April 2019b; 17:3. DOI: 10.14704/nq.2019.17.3.1999.

4. Lodish H, Berk A, Zipursky S L, Matsudaira P, Baltimore D and Darnell J. Molecular Cell Biology, 6th edition, Translation: Geçkil H, Özmen M, Yeşilada Ö, Palme Publishing, New York, 2018, 294-302.

5. Ölmez T.Is there an aesthetics in golden ratio as regards to the common cisregulatory Elements versus to atomic numbers of elements with respect to Quantum perspective model? Neurology and Neuroscience Reports 2020; Vol. 3. DOI: 10.15761/NNR.1000119

6. Wieser E M, Holden N, Coplen B T, Böhlke J K, Berglund M and Brand W A and et al. Atomic weights of the elements 2011, Pure and Application Chemistry 2013; 85(5): 1047-1078

\section{Internet References}

1. https://www.math.utah.edu/ 〜 pa/math/e.html December 08, 2020.

2. https://ipfs.io/ipfs/QmXoypizjW3WknFiJnKLwHCnL72vedxjQkDDP1mXWo6uco/ wiki/ Zebrafish.html December 09, 2020.

3. http://www.ncbi.nlm.nih.gov/pmc/articles/PMC3353008 December 08, 2020.

4. https://blast.ncbi.nlm.nih.gov/Blast.cgi December 08, 2020.

5. https://en.wikipedia.org/wiki/Phosphodiester bond December 08, 2020

6. https://www.britannica.com/animal/Denticipitidae December 08, 2020

7. https://www.ncbi.nlm.nih.gov/gene/114801900 December 08, 2020

8. https://en.wikipedia.org/wiki/Denticle_herring December 08, 2020

9. https://pubmed.ncbi.nlm.nih.gov/18687786/ December 08, 2020

10. https://pubmed.ncbi.nlm.nih.gov/31952464/ December 08, 2020

11. https://www.ncbi.nlm.nih.gov/protein/ADX59458.1?report=genbank\&log $\$=$ prottop \&blast ${ }^{\prime}$ rank $=96 \& R I D=X 1 Z 1 U 170013$ December 09, 2020

12. https://genetics.thetech.org/ask/ask69 December 09, 2020

13. CM Yang - arXiv preprint q-bio/0309014, 2003 - arxiv.org December 26, 2020. 